\title{
КРУГОВАЯ ЭКОНОМИКА КАК ПРИНЦИПИАЛЬНО ОСПАРИВАЕМАЯ КОНЦЕПЦИЯ
}

\author{
(c) 2018 Савченко Алёна Геннадьевна \\ Школа экономики и менеджмента \\ Дальневосточный федеральный университет \\ 690000, г. Владивосток, Океанский проспект, 19 \\ E-mail: savchenko-alenka@mail.ru
}

В данной статье рассмотрено понятие круговой экономики, ее отличительные особенности и характеристики. Доказана важность формируемой концепции в условиях устойчивого развития. Проведен сравнительный анализ характеристик круговой экономики и критериев принципиально оспариваемой теории, сделаны соответствующие выводы.

Ключевые слова: круговая экономика, экономическая стратегия, принципиально оспариваемая концепция, Галли, сопоставление.

В контексте борьбы с экологическими проблемами и переходу к устойчивому развитию всё большее внимание в последнее время получает концепция круговой экономики (Circular economy, CE). Причем обсуждения в основном проводятся на политическом уровне (Европейская комиссия, Фонд Эллен Макартур, организации по защите бизнеса и др.). По мнению экспертов, круговая экономика позволит задействовать механизмы, стимулирующие регенеративные промышленные преобразования, которые проложат путь для достижения устойчивого производства и потребления. При этом развитие промышленного производства на основе СE вместо преобладающих линейных моделей не только будет способствовать экономическому росту, но и окажет положительное влияние на окружающую среду.

Круговая экономика как потенциальная будущая промышленная парадигма рассматривается не только старыми индустриальными странами. Так, Китай был первой страной в мире, кто принял закон о введении циркулярной экономики (2008 год). После и Европейский Союз создал пакет документов в рамках развития данной концепции, расширив ранее принятую директиву по отходам.

Хотя идея материальных циклов возникла на заре индустриализации, она получила поддержку благодаря сегодняшним дискуссиям по смягчению последствий изменения климата и устойчивому развитию. В отличие от традиционной утилизации, концепция круговой экономики делает упор на повторное использование продуктов, компонентов и материалов, их восстановление, реконструкцию и модернизацию,

а также на потенциал устойчивых источников энергии, таких как солнечная энергия, энергия ветра, биомассы и отходов. Таким образом, понятие СЕ наряду с устойчивым производством направлено и на развитие устойчивого потребления.

Тем не менее, с научной точки зрения, исследование концепции СЕ находится на стадии становления. Всё отчетливее проявляется необходимость в более глубоком анализе концепции, ее единиц анализа, а также теоретических аспектов, лежащих в ее основе. Данный расклад позволяет говорить о том, что концепцию круговой экономики можно рассматривать как принципиально оспариваемую концепцию (либо «концепции, оспариваемые по существу»), понятие которой дал Галли в 1956 году. Данный термин, по его мнению, есть «концепция, правильное использование которой неизменно вызывает бесконечные споры об ее правильном использовании теми, кто её использует». Иными словами, концепция становится по существу оспариваемой, если существует согласие относительно средств и целей концепции, но возникают разногласия по поводу того, как ее определить, какие единицы анализа использовать, чтобы уловить динамизм, каковы концептуальные краеугольные камни и какая методология исследования является подходящей.

Исходя из вышесказанного, определяются две взаимозависимые цели исследования данной темы: анализ понятия круговой экономики, характерных черт и специфических особенностей и разработка проекта первоначального исследовательского подхода, с помощью которого можно проводить исследования по СЕ. В основе 
данной научной статьи лежит первая из целей.

Проводя обзор имеющейся литературы, стоит отметить, что существует множество определений понятия СЕ, которые, как правило, сформированы на основе фрагментированного набора идей, пришедших из различных научных областей и полунаучных концепций.

Существует более 20 определений круговой экономики, данными авторами из различных областей науки. В большинстве своем они имеют схожую основополагающую идею, но отличаются разными основами и углом рассмотрения понятия. В данной статье рассматривается наиболее обобщающее определение.

Круговая экономика - это промышленная система, которая носит восстановительный характер и подразумевает систему производства и потребления с минимальными потерями материалов и энергии благодаря обширному повторному использованию, переработке и утилизации.

К отличительным особенностям данной концепции можно отнести следующие вопросы к её характеристике: является она экономической стратегией, направлена на устранение отходов, защиту окружающей среды и предотвращение загрязнений, предлагает использование инновационных способов преобразования ресурсов, оптимизацию ресурсной доходности и минимизацию системных рисков.

Концепция круговой экономики подразумевает довольно понятную экономическую логику. Повторное использование продуктов или материалов, их восстановление и реконструкция (процессы «внутренних кругов») требуют меньших ресурсозатрат и являются более экономичными, чем обычная переработка и утилизация. При этом время, которое ресурсы проводят во «внутренних кругах» должно быть максимизировано. Другими словами, жизненные циклы ресурсов значительно увеличиваются, при этом они сохраняют максимально возможную ценность и качество как можно дольше, а также максимально экономно расходуют энергию. После того, как пригодное сырье извлечено, переработано и произведено с обычными затратами, имеет экономический смысл использовать произведенную стоимость как можно дольше, то есть как можно дольше сохранять продукт и его потребительскую стоимость в обороте.

Несмотря на то часть подходов, лежащих в основе концепции круговой экономики, внесли заметный вклад в науку и теорию перехода к устойчивому развитию, исследования данной концепции с использованием значимых теоретических основ довольно скудны. А недавние научные работы ряда учёных доказали, что существуют серьёзные барьеры и проблемы в практическом применении теории материальных циклов, возобновляемых источников энергии в системах производства и потребления и концепции в целом.

К ним относятся ограничения, связанные с термодинамикой, пространственными и временными границами системы, а также проблемы управления и управления, касающиеся межотраслевых и межорганизационных материальных и энергетических потоков.

Наличие множества разносторонних определений понятия круговой экономики объясняется тем, что концепция рассматривается с точек зрения различных заинтересованных сторон, включая политиков, предпринимателей, исследователей, потребителей и т.д. Единое универсальное определение граничит с не возможным и не должно предприниматься, потому что оно всегда исключало бы некоторые интересы, а также потому, что оно динамично и постоянно развивается.

Круговая экономика позволяет достигать некоторых политических целей, так как она воздействует на изменения климата, дефицита ресурсов и истощение биоразнообразия, а также на экономические проблемы неустойчивого развития, таких как рост цен на ресурсы и другие. Это способствует развитию инициатив в области устойчивого развития, которое первоначально было определено как развитие, отвечающее потребностям настоящего времени без ущерба для удовлетворения потребностей будущих поколений.

Несмотря на ряд доказанных преимуществ, концепцию круговой экономики зачастую называют принципиально оспариваемой. Галли определил концепцию как по существу оспариваемую, если она «может быть оспорена по причинам, но независимо от силы причин, которые они обычно несут с собой, и предполагает согласие относительно того, какой вид использования подходит для рассматриваемой концепции, между ее пользователем и любым, кто оспаривает его конкретное использование ».

Далее будет проанализирована круговая экономика в соответствии с семью критериями принципиально оспариваемой концепции. Начнем с того, что СЕ также построена, как ми- 
нимум, на четырех подконцепциях. Во-первых, промышленная экология, несомненно, является частью данной концепции с ее основным положением об особом внимании к циклическим, возобновляемым материальным и энергетическим потокам природы. Во-вторых, промышленный симбиоз фокусируется на данной теме в местных и региональных межорганизационных и межотраслевых сетях бизнеса. В-третьих, проект концентрируется на всей цепочке создания стоимости и жизненном цикле продукта или услуги и подчеркивает адаптацию социальных потоков к потокам природы, чтобы общество могло создавать полезные источники для природы и наоборот. В-четвертых, важной частью концепции является экономика совместного использования, поскольку она объединяет системы потребления с производственными системами.

Помимо того что принципиально оспариваемые концепции по Галли также состоят из подконцепций, они обладают семью специфическими свойствами. Первый атрибут заключается в том, что для этой концепции должно быть определено значение. В дискуссиях по СЕ очевидно, что концепция имеет большой потенциал. Остальные шесть особенностей - это внутренняя сложность, различная описательность, открытость, агрессивное и оборонительное использование, оригинальные образцы и прогрессивная конкуренция.

Внутренняя сложность концепции круговой экономика очевидна в предыдущих частях данной работы. С точки зрения различной описываемости, концепция СЕ несет в себе разнообразие описаний и различные типы аргументов. По поводу открытости Галли отмечает, что принципиально оспариваемая концепция должка быть открыта для пересмотра, изменения и модификации при изменении обстоятельств. Это актуально и для СЕ. Например, знания о нашем влиянии на окружающую среду являются неполными и постоянно меняются.

В отношении свойства «агрессивного и оборонительного использования» можно отметить, что СЕ является уникальной концепцией с точки зрения того, как быстро ему удалось завоевать ключевые позиции в ряде важнейших экономических и политических обсуждений, несмотря на достаточно малое количество фактических научных исследований в отношении концепции, их фрагментированность и неорганизованность.

Шестой критерий принципиально оспариваемой концепции, который мы используем, называется «оригинальный образец». Здесь Галли означает, что все пользователи концепции имеют тенденцию ссылаться на исторический авторитет. В СЕ единственным авторитетом является работа Кеннета Боулдинга на «Земле космического корабля» (1966), или работа Джорджа Рогена по термодинамике в экономических системах (1971), или уже цитируемая научная американская статья «Стратегии производства» Фроша и Галлопулос (1989).

Седьмой критерий - это то, что Галли называет прогрессивной конкуренцией. Это означает, что работа оригинального образца поддерживается, поскольку разные участники, применяющие эту концепцию, соревнуются в своих достижениях. Из анализа в данной статье ясно, что именно так обстоит дело с текущими дебатами по СE.

Наглядное сопоставление критериев принципиально оспариваемой концепции и характеристик круговой экономики приведено в табл. 1.

На основании вышеизложенного можно

Таблица 1. Сопоставление критериев принципиально оспариваемой концепции и характеристик круговой экономики

\begin{tabular}{|c|c|}
\hline $\begin{array}{l}\text { Критерии принципиально оспариваемой концепции } \\
\text { по Галли }\end{array}$ & Характеристики круговой экономики \\
\hline 1. Потенциальная ценность в концепции & Все общественные сектора заинтересованы в СЕ \\
\hline 2. Внутренняя сложность & Много аргументов за и против СЕ \\
\hline 3. Различная описуемость & $\begin{array}{l}\text { СЕ имеет много межотраслевых и межорганизацион- } \\
\text { ных интересов и предпочтений }\end{array}$ \\
\hline 4. Открытость & $\begin{array}{l}\text { Знания о воздействии устойчивости постоянно } \\
\text { развиваются }\end{array}$ \\
\hline 5. Агрессивное и оборонительное использование & Относительно мало критических исследований по СЕ \\
\hline 6. Оригинальный образец & $\begin{array}{l}\text { Боулдинг (1966), Роген (1971), Фрош и Галлопулос } \\
\text { (1989) }\end{array}$ \\
\hline 7. Прогрессивная конкуренция & $\begin{array}{l}\text { Различные субъекты продолжают предлагать свои } \\
\text { определения и применения СЕ }\end{array}$ \\
\hline
\end{tabular}


сделать вывод о том, что концепцию круговой экономики действительно можно квалифицировать как принципиально оспариваемую концепцию. Признание данного факта помогает в понимании концепции и дает возможность конструктивно ее использовать. Следовательно, существование различных и противоречивых взглядов на СE не должно служить оправданием скудных научных исследований и тем более не является барьером к более глубокому изучению.

\section{Библиографический список}

1. Graziela Darla, Araujo Galvãoa. Circular Economy: Overview of Barriers // Procedia CIRP. 2018. № 73. P. 79-85.

2. Vanessa Prieto-Sandoval, Carmen Jaca. Towards a consensus on the circular economy // Journal of Cleaner Production. 2018. № 179. P. 605-615.

3. Yuliya Kalmykova, Madumita Sadagopanb, Leonardo Rosadoc. Circular economy From review of theories and practices to development of implementation tools // Resources, Conservation and Recycling. № 135. 2018. P. 190201. 